\title{
Profundización del olvido de las personas mayores institucionalizadas durante la primera pandemia del siglo $X_{X I^{1}}$
}

\section{Evaristo Arcos Miranda}

(iD) https://orcid.org/0000-0002-2474-9046

Universidad Intercultural del Estado de México (UIEM), México

clandestino_7manonegra@yahoo.com.mx

\section{María del Rocío Echeverría González}

(iD) http://orcid.org/0000-0003-1571-8026

Universidad Intercultural del Estado de Puebla (UIEP), México

maria.echeverria@uiep.edu.mx

RESUMEN

La enfermedad provocada por el SARS-CoV-2 azotó al mundo al finalizar el año 2019, pero fue en 2020 cuando alcanzó a América Latina, y lo hizo con severidad. Ante su inminente desbordamiento, los sistemas de salud prescribieron el confinamiento como medida central para evitar su propagación y, ante todo, resguardar a las poblaciones vulnerables. El presente artículo se ocupa de este tema emergente bajo el supuesto de que las medidas de distanciamiento acentuarían el olvido familiar de las y los adultos mayores, en especial de quienes cursan el último tramo de vida en calidad de internos. A partir de un enfoque cualitativo, se analizó el impacto del fenómeno en las relaciones familiares de las y los envejecidos de una residencia situada en el Alto Balsas, Guerrero, detectando que la calamidad acentuó el desapego filial para con ellos, y concluyendo que, independientemente de las actuales circunstancias

Los autores reconocen el esfuerzo decisivo del inteligente evaluador / evaluadora de este artículo para orientar una exposición más clara de sus modestos aportes. 
sociosanitarias, las y los institucionalizados experimentan un estadio de olvido familiar alarmante.

Palabras clave: confinamiento, COVID-19, personas mayores institucionalizadas, olvido familiar y social, residencias geriátricas.

\title{
Deepening the forgetfulness of institutionalized older people during the first pandemic of the 21 st century
}

\author{
ABSTRACT
}

The disease caused by SARS-CoV-2 hit the world at the end of 2019, but it was in 2020 when it reached Latin America, and it did so severely. Faced with its imminent overflow, health systems prescribed confinement as a central measure to prevent its spread and, above all, to protect vulnerable populations. This article deals with this emerging issue, under the assumption that the distancing measures would accentuate the family forgetfulness of the elderly, especially those who are in the last stage of life as inmates. From a qualitative approach, the impact of the phenomenon on the family relationships of the elderly in a residence located in Alto Balsas, Guerrero was analyzed, detecting that the calamity accentuated filial detachment towards them, and concluding that, regardless of the current sociosanitary circumstances, the institutionalized experience an alarming stage of family forgetfulness.

Keywords: confinement, COVID-19, family and social forgetfulness, geriatric residences, institutionalized elderly women and men. 


\section{INTRODUCCIÓN}

El objetivo del presente trabajo es analizar, desde un enfoque cualitativo, el impacto del confinamiento instaurado como medida de protección ante la pandemia de COVID-19 en las relaciones familiares de las personas mayores institucionalizadas en la residencia «Adela Martínez», espacio explorado en años anteriores para la realización de una investigación doctoral que finalizó en 2019. La investigación avanzó bajo el supuesto de que el prolongado distanciamiento social debilitaría aún más las relaciones familiares de las y los internados, debido a que la irrupción de la pandemia en el escenario nacional obligó a la residencia a cerrar sus puertas a todo visitante.

Entre sus hallazgos principales, esta nueva indagatoria en la institución identificó que el encierro preventivo elevó a niveles perniciosos las sensaciones de abandono y olvido de las y los residentes — quienes en su gran mayoría no habían tenido contacto de ninguna naturaleza con sus familiares - , y asimismo, que las y los envejecidos abandonados por los suyos durante este periodo crítico se encontraban abandonados previamente, toda vez que la enfermedad provocada por el COVID-19, más que una causa, constituía un factor reafirmante de su situación.

Estudiar este nuevo abandono resulta fundamental para la comprensión del lugar que ocupan las personas mayores en la época contemporánea, y adelantamos que, pese al carácter binario del encierro: contención y refugio, en un contexto de profusión inexorable de la vejez (Powel, 2010)를 las residencias geriátricas de larga estadía desempeñarán un papel clave, por lo que es crucial su transformación

2 El envejecimiento poblacional cobrará ritmos diferentes en el mundo. En los países desarrollados se dará en lapsos que alcanzarán un siglo, en tanto que, para México, junto con casi todas las naciones en desarrollo, este cambio demográfico acaecerá de manera súbita (Powell, 2010; Garrocho y Campos, 2015; González, 2015). Powell (2010) remarca que, en los países menos desarrollados, el número de personas de edad avanzada aumentará a un 140\%, contra un 51\% en los países más desarrollados. En México, las personas mayores superan actualmente el 10\% de la población total, pero alcanzarán el 24,7\% en 2050 y, para ese entonces, su proporción se equiparará a la de los menores de quince años (González, 2015, p. 113). 
en verdaderos espacios de protección para la gran cantidad de personas que envejecen y envejecerán en condición de olvido.

La entidad de estudio se localiza en las colinas del lado sur de Huitzuco, localidad semirrural, ubicada en el Alto Balsas, en el estado de Guerrero, y, al igual que el resto de los centros poblacionales de la depresión del río Balsas, se encuentra en alto grado de marginación, la medida resumen que en México se utiliza para estimar la intensidad de las privaciones que padecen sus habitantes. El asilo, como lo denominan los lugareños, se fundó a mediados del decenio de 1980, a instancias de una familia que delegó su funcionamiento a un voluntariado, que a su vez buscó apoyo municipal para asegurar la retribución de algunos empleos y la provisión de despensas. La escasez de sus recaudaciones (sus aranceles han sido apenas significativos: actualmente equivalen a unos cien dólares mensuales por residente) se refleja en sus modestas instalaciones e implica necesariamente al voluntariado y la organización permanente de acciones en busca de conseguir fondos para solventar el gasto corriente. En virtud del secular maltrato intramuros de los institucionalizados e institucionalizadas - verificado por numerosas investigaciones-, es justo reconocer en este preámbulo que, sin duda, es su carácter no lucrativo lo que posiciona al centro estudiado como el mejor de la región (solo suele contar con tres o cuatro trabajadores remunerados).

La esperanza de vida se expande en la mayor parte del mundo. En México se enfila a superar las ocho décadas antes del medio siglo (Welti, 2018), y en no pocos casos, la vejez llega a abarcar cuarenta años de la vida de los seres humanos (Arcos, 2019) ${ }^{3}$. El aumento de la expectativa de vida, vinculado con el contexto de profusión de la vejez, llama a reflexionar - a escala familiar, comunitaria y estatal- sobre las duras condiciones en las que actualmente se desarrollan. Ante este porvenir inapelable, esta indagatoria identifica que, las instituciones geriátricas, aun las más desprovistas — como la entidad de estudio-, brindan los cuidados y la compañía indispensables a los adultos mayores durante la etapa más crítica de la vida, en la que la soledad y el abandono se vuelven los factores que más los aquejan y dañan (Arcos, 2019).

Envejecer en la casa donde realizó su vida conforma el desiderátum de toda persona, pero el proceso de transición demográfica es concomitante a otras transiciones, como el paso de la familia extensa a la nuclear y la reducción del

En menos de un siglo, la población mexicana ha duplicado su capacidad de sobrevivir. En 1930, la expectativa de vida era apenas de 33,8 años (Peláez, 2009); para el año 2000 era ya de 74 y para 2019 alcanzó los 75 años (Arcos, 2019). 
número de hijos por pareja. Estos cambios tornarán más complejo aun el envejecimiento en México. Un dato sobrecogedor apunta a que, a partir de 2030, una sola persona deberá encargarse del cuidado de hasta dos generaciones de sus predecesores (SEDESOL, 2010, p. 16). Por estos y otros factores que irán pronunciándose en los años venideros es prioritaria una atención especial a la investigación de las residencias geriátricas. En el presente - y, desde luego, en el futuro- de estos espacios se esperaría que constituyan lugares de resguardo y cobijo para las personas mayores, donde se les brinden los cuidados y atenciones necesarios para un envejecimiento saludable, en el cual la presencia de los suyos, aun programada, tenga lugar a través de contactos directos o de la comunicación a distancia. Empero, en rigor, la realidad actual dista mucho de tan grande aspiración. Tanto los resultados que reportan los estudiosos del tema como los de nuestro trabajo de campo, efectuado en diversos contextos y temporalidades, muestran de manera inequívoca que estos establecimientos hacen las veces de espacios de reclusión, donde, con demasiada frecuencia y por causas diversas, las familias internan a sus envejecidos con el objetivo de desprenderse de ellos y deslindarse definitivamente de la responsabilidad que conlleva su cuidado.

Concentrándose solo en el encierro, sus propósitos y sus efectos en el interno, tanto Goffman (2001) como Foucault (2015), autores de estudios clásicos sobre el internamiento en diferentes contextos históricos, los consideraron un recurso profundamente punitivo y coincidieron en lo agobiante que resultaba para el individuo privado de su libertad. Sus estudios ayudan a entender la institucionalización de la actualidad como un destierro que ubica a quienes avanzan en edad fuera de la sociedad, y que, eslabonado al repliegue de la responsabilidad filial hacia sus antecesores -impugnado en este trabajo - confirma al encierro como un proceso insoportable para ellas y ellos, cuando enfrentan una y otra vez el desentendimiento y el abandono total o relativo de la familia.

Este artículo está integrado por siete apartados. El primero es esta introducción; en el segundo, se explica la metodología empleada durante la indagatoria; en el tercer apartado se analiza la inseparable condición de encierro de las residencias para personas mayores del presente; el cuarto aborda la institucionalización como medida de protección; el quinto explica la situación de confinamiento sanitario y su manejo en la residencia estudiada; el sexto expone los resultados y su discusión a través de la selección de extractos de entrevistas, en los que se muestra el impacto del cierre de la institución en las relaciones filiales de las y los envejecidos; las conclusiones constituyen el séptimo apartado, y el trabajo finaliza con el listado de las obras citadas. 


\section{MÉTODO DE LA INVESTIGACIÓN}

A partir de la pandemia de COVID-19 que asuela el orbe, y el confinamiento como medida axial para evitar el contagio del virus que la provoca, se consideró importante analizar, desde un enfoque cualitativo, el impacto de esta estrategia de contención en las relaciones familiares de los adultos mayores institucionalizados en la residencia «Adela Martínez», espacio explorado en años anteriores, tal como se indica en la introducción. A pesar de ser el único espacio con el que cuenta la vejez desamparada en la región —o quizá por ello-, comúnmente se ha asumido que ahí van a parar los malos padres y los indigentes. Este arraigado supuesto obedece a que, desde su fundación, la residencia ha constituido la última morada de ex cargadores del mercado de la localidad, enfermos mentales y alcohólicos crónicos ${ }^{4}$. En estos casos que entrañan tan incomprendidos padecimientos, la residencia ha abierto sus puertas a pacientes mentales y de alcoholismo de apariencia envejecida, aun cuando no se aproximen ni al umbral de la llamada tercera edad (sesenta años, de acuerdo con la LDPAM, 2002).

El estigma planteado alcanza, desde luego, a los propios residentes, quienes, con frecuencia, hacen patente que antes de ingresar habían construido un patrimonio, que siempre «vieron» por sus hijos, que no eran bebedores, y a veces, desesperados, vierten comentarios en torno a la ingratitud de su descendencia y a que prácticamente llegaron engañados a la institución. En los no pocos casos en que estas confesiones fueron exteriorizadas, en el siguiente encuentro, incluso, al concluir la conversación, el informante dio marcha atrás, por lo que es frecuente que el caudal de la conversación exhiba estas contradicciones.

La investigación doctoral fue realizada desde un enfoque etnográfico y se empleó la entrevista semiestructurada. En el marco de la pandemia que causa estragos en diferentes estratos de la población que presenta comorbilidades —en especial en el sector de la tercera edad, a la que se considera de alta vulnerabilidad a la infección-, las entrevistas necesariamente tuvieron que efectuarse por vía telefónica, y dado que los residentes carecen de teléfono propio, fue determinante el apoyo del personal de la residencia, que hizo posible la comunicación a través de un teléfono celular que previamente se le proporcionó para la comunicación con las y los residentes. En vista de que nadie cuenta su vida a un grabador, de acuerdo con Mallimaci y Giménez (2012), y en este caso a un entrevistador

Ha de aclararse que, desde hace aproximadamente dos décadas, la mayoría de los residentes procede de otras demarcaciones municipales, e incluso, de otras entidades federativas, como Morelos y el estado de México. 
telefónico, las entrevistas trataron de seguir el patrón de una conversación para restaurar o lograr la confianza de años atrás, o conseguirla con quien no se entrevistó en los años previos, como en uno de los casos.

Con el apoyo de dos enfermeros que cubren turnos que abarcan el día completo y una trabajadora social, se estableció una agenda de comunicación en diferentes horarios. Las entrevistas se efectuaron en el mes de diciembre de 2020 y, entre otros temas, las preguntas giraron en torno al comportamiento de la comunicación entre los familiares y los internos a partir de que se prohibió su acceso a la institución, es decir, durante el largo confinamiento - aún en proceso - ordenado por las autoridades sanitarias, que en el centro entró en vigor el 23 de marzo de 2020, en virtud de la peligrosidad del COVID-19 y su alto poder de contagio.

La construcción de este trabajo, que da cuenta de la exacerbación del olvido de las y los envejecidos internados fue posible, dado que contó con la interiorización del contexto de estudio y un sólido proceso de inmersión conseguido a partir de la investigación efectuada en años recientes, condiciones de suyo inapreciables para esta nueva indagatoria. En el marco de la pandemia, se consideró pertinente ahondar en el tema del olvido, dado que los familiares del grupo de estudio, por diversas causas - casi todas vinculadas con la pobreza — no solían efectuar visitas constantes a sus predecesores internados.

El grupo de estudio se integró por diecisiete informantes: trece de ellos residentes, un enfermero, una enfermera y una trabajadora social. El rango de edad de los adultos mayores entrevistados fue de 76 a 87 años, que corresponde al de los residentes en su conjunto. Esta aclaración es pertinente debido a que, en 2020, fue recibido un señor de 54 años devastado por el alcoholismo. La institución cuenta actualmente con dieciséis plazas ocupadas de las veintitrés que ofrece, y fuera de ese caso excepcional, los dos adultos mayores restantes y con quienes se mantuvo contacto en años anteriores no pudieron ser entrevistados a causa de procesos de deterioro de su salud.

Consideramos que el enfoque cualitativo de la investigación —dado que permite comprender las singularidades de los fenómenos analizados (Cotán, 2016) - fue el apropiado para esta indagación que buscó la recuperación de las experiencias subjetivas de las y los informantes (Cotán, 2016), en este caso, los internos e internas y el personal de la residencia. Mediante la entrevista telefónica, se sostuvieron diálogos abiertos con los participantes (Castañeda y Jiménez, 2007) con el propósito de conocer de primera fuente las contrariedades que el cierre institucional causaba en su estado de ánimo, al negarse la entrada a visitantes y familiares. 


\section{Participantes}

Se entrevistó a trece institucionalizados: cinco mujeres y ocho varones. De ellos, solo una residente, por su reciente ingreso, no había colaborado en las indagatorias llevadas a cabo entre 2016 y 2019. Los criterios de inclusión de las personas adultas mayores en el estudio fueron: (i) que recordaran haber participado como informantes en investigaciones pasadas; (ii) que estuvieran de acuerdo en colaborar en caso de haber ingresado en 2020; (iii) que no presentaran problemas auditivos para comunicarse telefónicamente, y (iv) que consideraran afectadas sus relaciones familiares como resultado de la pandemia COVID-19 y que les interesara ser parte de la investigación. Con excepción del punto cuatro, los demás criterios fueron cubiertos por los trece adultos mayores en condiciones de ser entrevistados. Con los cuatro que continuaban gozando de cierta atención de los suyos, la comunicación solo tuvo como fin saludarlos y mantener vigente el agradecimiento por su participación anterior.

\section{Instrumentos}

La entrevista semiestructurada, sostenida vía telefónica, constó de una prueba piloto efectuada con uno de los institucionalizados con el propósito de verificar la pertinencia de los cuestionamientos. Las entrevistas se enfocaron principalmente en explorar la factible acentuación del distanciamiento familiar provocada por el confinamiento, centrándose en dos ejes temáticos: (i) cómo asumían el distanciamiento familiar resultado de la contingencia sanitaria, y (ii) qué afectaciones consideraban que tendría a su estatus familiar la ausencia de contacto con su descendencia.

\section{Procedimiento}

El contacto telefónico con los internos e internas de la residencia fue autorizado por la directora de la institución, a quien se explicó - también por vía telefónicaque la intención del estudio consistía en indagar el impacto del confinamiento - como medida de preservación de la pandemia - en las relaciones familiares y sociales de los mayores, y tuvo lugar en el mes de diciembre de 2020, como se ha señalado. Se explicó a los señores y señoras de manera puntal que el objetivo de las entrevistas tenía fines académicos, así como las temáticas que se abordarían. También se solicitó su autorización para la audiograbación de las conversaciones 
sostenidas, indicándoles que sus nombres reales serían remplazados por seudónimos. Se entrevistó a cada uno de los informantes en tres ocasiones, con el propósito de profundizar en las interrogantes planteadas. La información recuperada fue interpretada mediante el análisis de contenido, tal como proponen Castañeda y Jiménez (2007), en busca de comprender el impacto causado por las medidas de distanciamiento impuestas como protección contra la pandemia provocada por el COVID-19 en ellas y ellos.

\section{LAS RESIDENCIAS GERIÁTRICAS COMO INSTITUCIONES CERRADAS}

La institucionalización — podrá comprenderse — representa mucho más que un cambio de domicilio dado que, para los internos e internas, implica una modificación radical a su estilo de vida y un distanciamiento con su historia personal, que los desprende de su zona de confort (Ríos, Grajales y Valle, 2016), para enfrentarse a un contexto cerrado y desconocido en el que se encuentran separados de sus relaciones sociales y familiares, lo que les produce sensaciones de confusión y desamparo que afectan su personalidad e identidad individual.

El hermetismo propio de las residencias geriátricas las vuelve establecimientos de sujeción que aprisionan a las personas más que física, socialmente, pues en las instituciones cerradas ocurre la desaparición pública del individuo, cuyo símil es la muerte civil (Goffman, 2001), que conlleva la suspensión gradual de sus derechos e impide de manera tajante sus interacciones con el exterior. Así, el encierro, sin importar su naturaleza (punitiva, preventiva, formativa o protectora), afecta sobremanera la vida de quienes lo experimentan.

Foucault (2015) catalogó el encierro como un ritual de exclusión que desprendía a los sujetos de la sociedad y lo describe como un mecanismo de contención que distancia a una población de las demás, lo que lo vuelve un dispositivo de separación que coloca a aquellos indeseables al margen de la comunidad. El encierro - según él — representa un principio de segregación que silencia e invisibiliza a sectores específicos puntuales, considerados incapaces de continuar formando parte del aparato social, como los delincuentes, locos, vagabundos, ancianos, etc. (Foucault, 2012).

Desde una perspectiva sociológica, Goffman (2001) analizó el encierro como un confinamiento que desvanece los roles sociales de los individuos, quienes al encontrarse internados se ven imposibilitados de continuar ejecutándolos. Esta suspensión irrevocable - agrega el autor-muestra al sujeto su nueva condición, 
que le impide proseguir activo dentro del ciclo de la vida y lo mantiene externo a las determinaciones familiares y decisiones ciudadanas. En esta circunstancia, el interno «ha perdido ciertos roles en virtud de la barrera que lo separa del mundo exterior» (2001, p. 28). Y como si la humanidad no hubiera recorrido ya un largo camino hacia la reafirmación de sus derechos, en estudios recientes sobre el encierro resuena el eco de las tesis canónicas de Foucault y Goffman. Danel (2008), por ejemplo, señala que el encierro es incapacitante y suspensivo de los derechos de los individuos como ciudadanos, y en la misma línea incriminatoria, Paz (2010) asevera que el encierro constituye para el individuo uno de los castigos más severos y traumáticos.

En síntesis, las residencias geriátricas, ineludiblemente vinculadas con el encierro, reducen y obstaculizan el desarrollo social y familiar de los internos e internas, quienes, al ser impedidos para relacionarse abierta y libremente, ven periclitar sus relaciones sociales y afectivas de manera drástica, al punto de ser olvidados por su propia descendencia.

\section{INSTITUCIONALIZACIÓN COMO MEDIDA DE PROTECCIÓN}

Dado que en los últimos años ha predominado una visión sesgada de la vejez, que la concibe únicamente como una etapa de menoscabo y pérdida (Arcos, 2019), cabe resaltar que, esta perspectiva propendió a los ancianos a un desplazamiento gradual de su preponderancia como personas de experiencia, conocimiento y sabiduría (Reyes, 2012). Este desplazamiento se materializó en abandono familiar y otras formas de maltrato, al grado de conducir al aparato estatal mexicano, a generar leyes que obligan a las familias a responsabilizarse de sus adultos mayores (LDPAM, 2002), y a la creación de espacios destinados al cuidado y atención de la sociedad en edad avanzada.

Sea por esta mudanza de la imagen social de los adultos mayores, sea por su acelerada profusión, las residencias son cada vez más importantes en la estructuración social. Fungen como espacios de abrigo para quienes alcanzaron el cenital de la vida sin forjar un patrimonio y en condiciones de absoluta vulnerabilidad, que resultan una carga para sus consanguíneos (Arcos, 2019). La institucionalización configura una medida de resguardo, que, si bien destierra a las personas adultas mayores de la sociedad, las mantiene seguras, alejadas de las contrariedades de la vida familiar y comunitaria (Ruiz et al., 2001). 
En sus estudios sobre ancianidad desprotegida, Ruiz y Hernández (2009) destacan que «las víctimas de violencia tienen en común su vulnerabilidad, la cual obedece a muy diversos factores como su condición de dependencia económica y/o afectiva» (p. 147). Esta doble dependencia tiene, entre sus orígenes más comunes, la carencia y la pérdida de cercanos (cónyuge, amigos, conocidos), por lo que, las personas mayores en circunstancias de pobreza y soledad son altamente proclives al maltrato dentro del seno familiar, de manera especial en los hogares de bajos recursos económicos o carentes de espacio donde los envejecidos se ven orillados a competir con otros miembros de la familia por el acceso a los bienes y servicios (Robles et al., 2006). En este contexto, la institucionalización se vuelve fundamental para la salvaguarda de personas de edad avanzada que viven o son proclives a atravesar situaciones de maltrato.

\section{LA PRIMERA PANDEMIA DEL SIGLO XXI}

Los primeros brotes de la epidemia respiratoria de COVID-19 se registraron en China a finales de 2019, pero por la rápida propagación del contagio, para el 12 de marzo de 2020 fue declarada pandemia por la OMS, y solo tres días después, las autoridades mexicanas ordenaron el cierre de las escuelas e iniciaron una vigorosa campaña de distanciamiento social que implicó la cancelación de todo tipo de actividades que propiciaran aglomeraciones, al grado que, en algunas entidades federativas, se aplicaron toques de queda y se restringió el tránsito peatonal y vehicular para forzar a su sociedad al aislamiento.

La entidad de estudio - se ha informado - fue cerrada a los visitantes a partir del 23 de marzo de 2020. Esta estrategia de preservación, junto con otras que separaban aún más a los internos del mundo exterior, dio como resultado una especie de encriptación o encierro doble de los residentes, lo que contribuyó a elevar a grados perniciosos las sensaciones de abandono que los mortificaban desde tiempo atrás. De esta forma, ante las medidas de distanciamiento que contemplaron el cese del transporte colectivo y provocaron la pérdida de empleos, hizo aparición un abandono cuasi definitivo de los internos e internas por sus familiares, quienes en principio no tuvieron forma de trasladarse al lugar donde se encuentra la residencia.

Pero a la peligrosidad objetiva del COVID-19, pronto se agregó otra, esta subjetiva y más aterradora por asociarse fuertemente a los prejuicios. Debido a que las primeras variantes no fueron estrictamente lesivas para jóvenes e infantes, empezó a verse a las personas de edad avanzada como una doble amenaza. En este 
imaginario, por un lado, representaban una segura fuente de contagio, y, por otro, predominaba la idea de que los escasos equipos hospitalarios fueran reservados a las personas en edad productiva. Bajo este esquema mental, el edadismo y la gerontofobia, ya presentes en la sociedad mexicana, cobraron un rostro brutal; el primero concibe normal la discriminación sistemática de las personas de edad avanzada, y el segundo alude a «un profundo prejuicio que se manifiesta en estereotipos y mitos, desprecio, disgusto o simplemente el evitamiento sutil» (Parres, 2003, p. 309). En el mismo orden, otros hechos que podrían ayudar a comprender la gravedad de estas predisposiciones hacia las personas mayores fueron las agresiones desencadenadas contra el personal médico en espacios públicos, registrados en distintas ciudades mexicanas durante los primeros meses de la pandemia.

En este escenario, las cuestiones subjetivas coadyuvaron a tender un manto de olvido sobre los internos e internas por sus descendientes, que dieron lugar a un abandono profundo y dañino al cortar de tajo la comunicación con la mayoría de ellos, y dar lugar a una ausencia física desesperanzadora. Este trabajo considera fundamental analizar el recrudecimiento del olvido durante el primer año de confinamiento sanitario en la entidad de estudio, dado que, es preciso aprender de esta experiencia, no solo por descartar que el olvido sea privativo de este centro, sino porque, según la OMS, un regreso a la normalidad como la conocimos ya no será posible, y porque la humanidad solo transita por la primera pandemia del siglo XXI.

\section{RESULTADOS Y DISCUSIÓN: OLVIDO, ABANDONO Y ENCIERRO}

El olvido de las personas mayores conforma el ápice visible de una sociedad que prioriza su bienestar por encima del de sus envejecidos, y, en el caso extremo, opta por un internamiento irrevocable que solo concluirá con su muerte. Olvido, abandono y encierro — digámoslo así — se adscriben al mismo campo semántico. Según el diccionario de la Real Academia Española, olvido es la «cesación del afecto que se tenía»; abandono es el «efecto de abandonar o abandonarse», y encierro significa «clausura, recogimiento». Al resonar estas significaciones en las entrevistas sostenidas con quienes experimentaban estas esclerotizadas formas de maltrato: «Aquí ya no le estorbas a ninguno»o «Cuando tus hijos te dicen te vas al asilo, pues ya sabes por qué», a lo largo del trabajo estas nociones se tratan como equivalentes. A la luz de la experiencia observada, sostenemos que el abandono de los internados e internadas no es otra cosa que el desentendimiento radical de sus familiares hacia ellos y ellas, que de manera intrínseca contempla 
la cancelación de una comunicación que pudiera llenar su ausencia y cuyo precedente - la institucionalización misma - conforma el elemento tangible.

En la entidad de estudio, el encierro de las personas adultas mayores conforma la expresión material del proyecto de olvido del que son portadores y que fue concebido por los suyos tiempo atrás, cuando empezaron a resentir el minuendo de sus aportes y a visualizar su internamiento como una ventaja inestimable para sí mismos. Si bien este proyecto de olvido puede desencadenarse a partir de eventos catastróficos - como la viudez (el caso de la generalidad del grupo estudiado), una enfermedad incapacitante o pérdida de patrimonio-, también entra en juego el desdibujamiento de los roles que determinaban la implicación vital del adulto mayor en su grupo familiar, como dejar atrás su papel de proveedor, en el ámbito puramente material, o de abuela/o-niñera/o en el ámbito de la reproducción social. En síntesis, desde este particular marco de observación, para los institucionalizados e institucionalizadas, el encierro constituye la prueba tangible del olvido de los suyos, y el abandono - la pauta de conducta que lo materializa-, la ratificación de su ingratitud.

Los extractos incluidos en este apartado exponen narrativas que abordan temas como la llegada de los y las residentes a la institución y el abandono filial del que eran objeto, lo que se agudizó con el confinamiento sanitario. A una fuerte sensación de pérdida real de su libertad y de erosión de su estatus social, otras sensaciones permean sus relatos, como un intenso sufrimiento y un perturbador desasosiego por desconocer lo que pasaba a los suyos, quienes no solo no acudían a verlos «de lejecitos» sino que, tampoco les dejaban algún «recadito» para saber cómo estaban.

El confinamiento sanitario que determinó la suspensión de las visitas a la residencia, en tanto contribuyó a incrementar la ansiedad de los internos e internas, dio lugar a la profundización de su sensación de abandono. El cierre de sus puertas hasta nuevo aviso constituiría, a la postre, una medida del todo lesiva para el equilibrio emocional de los internos e internas, quienes, desde el tiempo previo ya se desarrollaban en atmósferas de olvido, dado que las visitas de sus familiares eran esporádicas en algunos casos y demasiado erráticas y espaciadas en otros. A pesar de sus preocupaciones en torno a un posible agravamiento del abandono de los adultos mayores por su grupo filial, entre los responsables de la residencia pesó más la preocupación de que la población internada fuera estragada por el COVID-19, por lo que era imperativo cumplir una clausura total, que en un principio se concibió por un plazo que no sobrepasaría los cuarenta días y así lo anunciaron a las familias. 
En este marco, el abandono - al igual que el encierro y una inquietud abrumadora por saber cómo estaban los suyos durante la pandemia - conforma una transversal en los relatos que se incluyen a continuación. El encierro, precisa Paz (2010), estructura un principio de separación que destierra a los sujetos de la realidad, manteniéndolos inmóviles e incomunicados: «Estar encerrado sin saber nada sientes que te estás muriendo», pero esta incomunicación era verdaderamente traumática para los internados e internadas durante el periodo de estudio debido a que, a la secular falta de libertad de las residencias geriátricas, se adicionaron los múltiples impedimentos de las medidas sanitarias, conduciéndolos a una desolación sin precedentes. En la narrativa de la señora Arcelia, por ejemplo, persiste una clara invocación de esperanza: «Ya sabes que no vienen, pero tú esperas», que le permite vivir cada día, y, en general, el tedio es otro tema que impregna los segmentos, pues sin nada productivo que hacer, los internados e internadas se desenvolvían bajo ciclos de repetición (Foucault, 2012), inherentes a la rutina de la institución, en un presente poblado de temores que los aturdían y destemplaban: «Yo, la verdad, ya no aguanto», transformando la esperanza de ser visitados en frustración e impotencia.

Encerrada, aquí, ya no puedes salir [...] sientes que te mueres sin saber de nada, un recadito, nada. Sin ver a nadie que venga es lo más triste (señora Esther, 78 años, dos años y medio institucionalizada, entrevista 31/12/2020).

Estos, con enfermedad, sin enfermedad, de por sí no venían [...] Si quisieran, pues hasta de lejos nos pueden alzar la mano, ¿qué les puede pasar? (señora Cecilia, 78 años, cuatro años institucionalizada, entrevista 22/12/2020).

[...] Ya sabes que no vienen, pero tú esperas, y no vienen, eso de estar siempre lejos de la casa te da preocupación, te martiriza $[. .$.$] y ni aución { }^{5}$ de que vengan (señora Arcelia, 77 años, dos años institucionalizada, entrevista 18/12/2020).

[...] No puedes hacer nada de lo que hacías antes. Estar encerrado sin saber nada sientes que te estás muriendo. Quieres saber, que te hablen, aunque no te den de comer (señor Genaro, 81 años, dos años institucionalizado, entrevista 15/12/2020).

[...] La familia no va venir a vernos, ya no les importa lo que pase [...] Aquí nos dicen que cuando acabe [la pandemia] van a venir los hijos, pero adivinar [...] Yo la verdad ya no aguanto (señora Margarita, 76 años, un año institucionalizada, entrevista 25/12/2020).

5 Es un localismo relacionado con la esperanza. 
Cuando te vienes pa' acá, que vas llegando, ni te imaginas cómo va ser de verdad, no crees que no vas a ver a nadie, que no te van a hablar. Dicen que esto a los de la tercera edad los mata, y no llaman [...] Yo ya ni quiero ver pa' fuera, ya sé que para mí no vienen (señor Ernesto, 79 años, dos años institucionalizado, entrevista 22/12/2020).

[...] Desde que estoy aquí, ya no me toca verlos casi nunca, de por sí la gente no viene mucho a estos lugares [...] Aquí encerrado, estás piense y piense, y le pides a Dios que estén bien [...] (señor Gustavo, 82 años, cuatro años institucionalizado, entrevista 15/12/2020).

Esta enfermedad vino a acabar con todo, nos estamos quedando solos aquí [...] Nadie se te puede acercar [...] No poder salir, te sientes preso, sin haber hecho nada malo, nomás por tu pobreza (señor Juan, 84 años, cinco años institucionalizado, entrevista 29/12/2020).

La situación de don Juan refleja la de la generalidad de los entrevistados y entrevistadas, que al igual que él, fueron llevados «con engaños» a la institución y cuyo internamiento fue precedido por una serie de maltratos que incluían el abandono. Ante ello, señalamos que, es este contexto de franca renuncia filial al deber moral de ver por sus ascendientes, lo que nos conduce a afirmar que la institucionalización se vuelve fundamental para la salvaguarda de quienes son proclives a atravesar situaciones de dificultad. Es preciso, sin embargo, advertir la paradoja de las residencias geriátricas de larga estadía referida al hecho de que, en tanto condenan a las personas mayores al encierro, también las preservan de peligros, procurándoles un espacio en el que puedan ser atendidas y cuidadas, pues, sin el recurso de internamiento, muchos adultos mayores se expondrían aún más a situaciones oprobiosas, al continuar viviendo rechazados en su grupo familiar o en ambientes hostiles que erosionan su calidad de vida y vilipendian su lugar social (De la Serna, 2003; Robles et al., 2006, Reyes, 2012).

A la paradoja planteada, debe agregarse también que el olvido forma parte de los grandes riesgos de la separación de las personas envejecidas de la corriente de la vida, pues para muchas de ellas la institucionalización llega a convertirse en una franca clausura vital, $\mathrm{y}$, si bien esta puede presentarse en forma súbita — como más adelante ilustrará el caso de don Samuel-, el trabajo de campo efectuado en la entidad de estudio antes del confinamiento sanitario nos permitió identificar cuatro estadios de duración variable del olvido más sentido para ellas: el filial. En el primero, el olvido no es palmario, pues el adulto mayor es frecuentado con una periodicidad no inferior a las dos o cuatro semanas. Un segundo estadio contempla visitas más espaciadas, pero que no llegan a superar intervalos de dos meses. 
En el tercer estadio se registra una reducción drástica de las visitas, que además se vuelven erráticas, posiblemente porque ya son menos los descendientes que asumen la responsabilidad de frecuentarlos, y el interno ha agotado sus reservas (ropa, calzado, cosméticos, rastrillos para afeitarse, ciertos alimentos, etc.) y comienza a exigir efectivo a sus visitantes, quienes también suelen ser blanco de reproches. En el cuarto y último estadio, el alejamiento es casi definitivo o definitivo al grado de que el pago de aranceles se efectúa en forma indirecta y, en casos extremos, se deja de cubrir.

En este pequeño universo observado, ante los estragos del olvido, una vez intuida la conducta de alejamiento de los parientes del interno, sobre todo, en el cuarto y más dramático estadio de olvido —en tiempos normales - la institución pone en práctica sus propios mecanismos tácticos persuasivos. Uno de ellos es la condonación de los aranceles, pero demanda a la familia continuar visitando a su predecesor, dado que la residencia se asume competente para proporcionarle cuidados integrales, pero reconoce su incapacidad para subsanar el vacío que deja la suspensión de los afectos filiales en la persona mayor.

Pero de manera previa, desde una perspectiva de largo plazo, uno de los mecanismos estratégicos institucionales en busca de impedir la irrupción del olvido - considerando la pertenencia generalizada de los internados e internadas a grupos socioeconómicos desfavorecidos y su ubicación geográfica semiaisladaconsiste en flexibilizar los horarios de visita, e incluso, ofrecer alojamiento y alimentos a los familiares que proceden de lugares distantes para promover el acercamiento con los suyos. Empero, pese a sus mecanismos — sobre todo en el crítico periodo que se analiza-, no siempre los esfuerzos que la institución emprende han sido fructíferos para mantener la estabilidad emocional de las internas e internos insertos en dinámicas de olvido.

En los siguientes segmentos, desde una perspectiva de género, podrá valorarse que las y los residentes, de manera casi directa, invocan el modelo tradicional de feminidad en el que los padres esperan más de las hijas que de los hijos, bajo la idea de que son ellas quienes deben brindarles una mejor atención como una extensión de su rol tradicional (Delicado et al., 2001), y si los visitaban, era imperdonable que se retiraran pronto, como en el caso de la hija de doña Margarita, quien sufría pobreza de tiempo, y se desesperaba porque acudía solo en contadas ocasiones y pasaba poco tiempo con ella. Don Gustavo asumía que quienes lo hacían sentir «arrimado» eran sus hijas o sus nueras y descargaba a sus hijos de toda responsabilidad. Durante las entrevistas era patente esta pauta cultural entre 
las y los institucionalizados, al asumir que su atención y visitas de calidad debían exigírseles a las hijas, liberando a los hijos varones de tal compromiso

[...] sus mujeres no les gusta eso de que estés en su casa, te ponen modo, ya de señor grande mejor aquí, porque pues, aquí ya no le estorbas a ninguno (señor Gustavo, 82 años, cuatro años institucionalizado, entrevista 15/12/2020).

[...] cuando llegan a venir, luego se van. Una vez vino la menor como cinco minutos, ya ni la burla. Pienso que ya no les interesa [...] Pero yo soy su mamá y ni así hacen visitas (señora Margarita, 76 años, un año institucionalizada, entrevista 25/12/2020).

El abandono, sin embargo, debe verse con todos sus matices, pues es importante reconocer que, a diferencia de las clases favorecidas — en las que a menudo se interna y se deja de frecuentar a las personas mayores por razones distintas de la pobreza (Iglesias, 2001) —, el olvido del que eran objeto los institucionalizados e institucionalizadas del grupo de estudio también cobraba un carácter estructural, pues en un escenario de penuria económica, en realidad las familias no siempre podían encargarse de todos sus integrantes, y en esencia, a ello se debía que trasladaran esta obligación al sistema (Cardona y Peláez, 2012) o, en este caso, a la sociedad. Frecuentarlos les implicaba precisamente costos y, para ellas y ellos era menester priorizar el pago de los aranceles antes que las visitas. En sus relatos, algunos participantes hacen referencia clara a estos escenarios de pobreza.

No me tienen que dar dinero, ya se los he dicho, que nomás vengan, que lo que quiero es verlos. Uno aquí piense y piense, ¿y si no vienen porque les pasó algo que no nos quieran decir ni los voluntarios? (señora Cecilia, 79 años, cuatro años institucionalizada, entrevista 22/12/2020).

Cuando tus hijos te dicen «te vas al asilo», pues ya sabes por qué [...] si ya no quieren que estés ahí, si ya no te quieren dar de comer (señor Samuel, 82 años, tres años institucionalizado, entrevista 19/12/2020).

Unos mis hijos nunca han venido, para no gastar, no hablan. Se impone uno a estar aquí, sabes que no vas a ver a nadie (señor Gustavo, 82 años, cuatro años institucionalizado, entrevista 15/12/2020).

Por último, sobre todo en el marco de la pandemia, en una institución en la que se cursa el último tramo de la existencia, era natural que prevaleciera una subjetividad relacionada con una irrefutable fatalidad del destino («al que le toca, le toca») entre los internos e internas. En algunas entrevistas, por ejemplo, era 
palpable que ponían en duda la letalidad del contagio, y que solo se había convertido en un poderoso subterfugio para olvidarlos para siempre, y podía acaecer su muerte sin que los suyos se enteraran. El personal de la institución, por su parte, trataba de reconfortarlos diciéndoles que en un tiempo próximo terminaría la crisis sanitaria y que no estuvieran tristes, pues pronto verían a sus hijos e hijas, labor inestimable en virtud de que la depresión es uno de los padecimientos más recurrentes en la vejez (Bautista, 2016), que con frecuencia conduce a otros padecimientos físicos y, en casos extremos, al suicidio (De la Serna, 2003).

[...] muchos están pensando en que se van a morir y nadie va a ver por ellos. A mí me vinieron a ver desde el otro diciembre, ya me largaron aquí (señor Samuel, 83 años, tres años institucionalizado, entrevista 19/12/2020).

En su narrativa, don Samuel se deslinda de quienes aún tienen esperanza de ser frecuentados por los suyos: «Ya no viene nadie a verlos». Y es que, a pesar de su ingreso reciente a la institución, estaba a punto de cumplir un año sin recibir un solo visitante, por lo que una fuerte sensación de abandono impregna su testimonio. En él verbaliza, además, un temor generalizado que no se pronuncia en primera persona: el morir entre extraños, lejos de su familia.

«De todos los que llevan al asilo, nadie regresa a su casa: llegan para quedarse hasta que fallecen. Tratamos de sobrellevarlos, pero ellos lo saben» (ex directora de la residencia geriátrica, entrevista 03/01/2021). El encierro es una paliza para el alma, señala Paz (2010). Su poderosa metáfora ilustra con precisión la punzante certeza de libertad conculcada por los internos e internas («cuando ya vives aquí, ya no te dejan irte»), semejante a la muerte civil descrita por Goffman (2001), porque concierne la suspensión gradual de los derechos de los institucionalizados e institucionalizadas y, además, impide de manera tajante sus interacciones con el exterior.

Aquí, cómo le dijera yo, hasta como que se te van olvidando las cosas, y la familia se va desentendiendo; ya viejo, ya no mira por uno con la edad. A mí me vinieron a dejar y sin venirme a ver cómo estoy (señor Juan, 84 años, cinco años institucionalizado, entrevista 29/12/2020).

La invocación de don Juan encara la asunción de que «al asilo van a parar los malos padres» reinante en la localidad, al reprochar, por el contrario, la ingratitud de sus familiares por haberlo abandonado, lo que, de acuerdo con Leinaweaver (2019), demostraría una línea «de falla dentro de los lazos de parentesco» (p. 179), pues él siempre los socorrió, y ellos, en cambio, se desentendían de su cuidado. El internamiento forzado - como se ha señalado - no era privativo de 
don Juan, solo que, en algunos casos, esta imposición había sido atenuada por una autoconvicción en la que subyacía la idea de que su salida del entorno filial liberaría a los suyos de mayores penurias.

En este análisis, es importante reconocer que, en el tiempo anterior a la pandemia, múltiples causas asociadas no solo a sus bajos ingresos, sino también a padecimientos, impedían a algunos de sus descendientes una visita regular a sus progenitores internados. En el curso de las entrevistas se ha indicado, cuando los reclamos hacia sus descendientes se endurecían, en alguna inflexión de la charla — o a veces al final— que los y las participantes solían dar marcha atrás con un «es que casi no tienen trabajo», «no viene por su enfermedad». Esta perspectiva de reconocimiento de los problemas de sus descendientes llegaba a desvanecerse por la desolación que les causaba un encierro sin noticias, sin las palabras de aliento de un familiar que los resituara de nueva cuenta en la certeza de que su sacrificio tenía algún sentido. Empero, con los discursos acusatorios y su contraparte - la disculpa no instada-, se buscaba gestionar interiormente la contradicción de hablar duramente de un hijo o hija, al mismo tiempo que no dejaba de querérsele, de soñársele y extrañársele (Delacroix, 2020).

\section{CONCLUSIONES}

En esta investigación se ha analizado cómo el acaecimiento de la pandemia causada por el COVID-19, al orillar a las residencias geriátricas de larga estadía a tomar como medida preventiva la cancelación del paso a visitantes, agudizó el abandono familiar de las personas adultas mayores, incrementando con ello sus sensaciones perturbadoras de incertidumbre, vulnerabilidad, malestar y desamparo. Los datos primarios recabados a partir de las entrevistas telefónicas levantadas para este estudio muestran la profundización del debilitamiento y deterioro de sus relaciones familiares en este periodo especial que ya roza el año.

Expresiones de indubitable anulación previa de la presencia del adulto mayor en la familia permiten concluir que, en tanto la institucionalización de las personas de edad avanzada suele ser precedida por una serie de desencuentros familiares no exentos de violencia, el olvido que enfrentan una vez institucionalizadas conforma la consecuencia lógica de esa serie de rompimientos filiales y sociales que los fueron haciendo candidatos al encierro, y es el olvido familiar y social el que ahonda el malestar del encierro y define para ellas y ellos una condición de profunda vulnerabilidad, tal como exponen los entrevistados. 
El abandono de los internados e internadas en la residencia estudiada los hace proclives a sufrir depresión, uno de los problemas de salud más generalizado en la edad avanzada. Los fragmentos de entrevistas incluidos en este trabajo evidencian una incertidumbre que se adensa en algunos de ellos y ellas, debido a que, el olvido que los atormenta no solo tiene que ver con el yo de los envejecidos, sino que este implica también preocupaciones extremas por el desconocimiento de lo que pueda estar ocurriendo a los suyos.

La condición de abandono en que se encuentran los mayores ha tenido un notorio incremento durante este periodo crítico y revela el estado de vulnerabilidad en que se encuentra la vejez en nuestros días, especialmente la que cursa esta etapa en instituciones cerradas. A pesar de reconocer la compañía y diligencia del personal de la residencia, los entrevistados y entrevistadas echaban de menos sobremanera las visitas de sus familiares, por quienes sentían cariño, identificación y confianza para solicitarles artículos que les hacían falta.

Aún en este clamor exhibido en los extractos por saber de los suyos y satisfacer sus necesidades de afecto, tiene sentido aclarar que los internos e internas daban muestras de inequívoca comprensión sobre las imposibilidades reales de sus hijos para visitarlos, y que en esta empatía subyacía la conciencia y aceptación de su papel de relegados filiales y sociales. Sin embargo, pese a estas muestras de empatía para una sociedad que posterga a sus predecesores, es importante aclarar que el abandono de las personas mayores no es privativo de la institución estudiada, y ni siquiera se circunscribe al crítico periodo de la pandemia de COVID-19, sino que, de acuerdo con las investigaciones revisadas, actualmente constituye un grave fenómeno que interpela los principios éticos de la humanidad, al haberse convertido en un problema público. Son tan comprometedores los estragos que ocasiona el abandono en la salud física y psicológica de las personas envejecidas que la OMS los ha catalogado como una de las manifestaciones de maltrato más acuciantes. Las aristas más desgarradoras de este fenómeno están conformadas por el aislamiento y la incomunicación (Fernández y Herrero, 2006). Estos factores, como puede advertirse en los testimonios, adoptan dimensiones aún más dramáticas en circunstancias de institucionalización, toda vez que la condición de encierro determina que los internos e internas desarrollen su proceso vital bajo la negación familiar y, a raíz de la conculcación de su libertad, los privan de continuar formando parte del flujo de la vida.

Por último, no debe soslayarse que el olvido familiar y social en el que se encuentran los institucionalizados e institucionalizadas se encuentra inserto en un avanzado proceso de transición demográfica hacia el envejecimiento poblacional 
en México (González, 2015), y es en este escenario de profusión inminente de la población longeva que la trasformación de las instituciones geriátricas de espacios cerrados a establecimientos integrales, con capacidad de promover un proceso de envejecimiento saludable, se vuelve un imperativo inaplazable, toda vez que gran parte de las personas mayores, una vez internadas, solo cuentan con el apoyo institucional. La larga duración de la primera pandemia del siglo XXI dejó ver la ingente necesidad de dotar de equipos y de entrenamiento al personal asistente para facilitar la comunicación del exterior con los internos e internas. Esta medida sería factible, dado el acceso sin costo a las redes sociales. De esta forma, la generación de residencias especializadas en atender los requerimientos sociales, emocionales y físicos de las personas de edad avanzada promovería una vejez digna para todos aquellos que cursan este periodo en condiciones de vulnerabilidad y abandono extremo.

\section{REFERENCIAS}

Arcos, E. (2019). Función sociocultural de la institución asilar Adela Martínez, zona rural del Alto Balsas, Guerrero. Tesis doctoral, Colegio de Posgraduados. México: Montecillo, Estado de México.

Bárcena, C., Iglesias, J., Galán, M. y Abella, V. (2009) Dependencia y edadismo. Implicaciones para el cuidado. Revista Enfermería CyL, 1(1), 46-52. file://C:/Users/ user/Downloads/18-67-3-PB.pdf

Bautista, J. (2016). Depresión en el adulto mayor por abandono familiar. Tlatemoani: Revista Académica de Investigación, 7(22), 226-271.

Cardona, D. y Peláez E. (2012). Envejecimiento poblacional en el siglo XXI: oportunidades, retos y preocupaciones. Salud Uninorte, 28(2), 335-348.

Castañeda, D. y Jiménez, L. (2007). La entrevista telefónica. Estudios sobre las Culturas Contemporáneas, 8(26), 137-162.

Cotán, A. (2016). El sentido de la investigación cualitativa. Escuela Abierta, 19, 33-48. https://doi.org/10.29257/EA19.2016.03

Danel, P. (2008). Adultos mayores institucionalizados: objetos de protección, cuidado y rentabilidad. En Jornadas de Cuerpo y Cultura de la UNLP, Universidad Nacional de la Plata.

De la Serna, I. (2003). La vejez desconocida: una mirada desde la biología a la cultura. España: Díaz de Santos. 
Delacroix, D. (2020). La presencia de la ausencia: hacia una antropología de la vida póstuma de los desaparecidos en el Perú. ÍCONOS, Revista de Ciencias Sociales, 67, 61-74. https://doi.org/10.17141/iconos.67.2020.4141

Delicado, V., García, M., López, B. y Sánchez, P. (2001). Cuidadoras informales: una perspectiva de género. Revista de Enfermería, 13, 12-16.

Fernández, M. y Herrero, S. (2006). Maltrato en el anciano: posibilidades de intervención desde la atención primaria. Atención Primaria, 37(1), 56-59. https://doi. org/10.1157/13083927

Foucault, M. (2012). Historia de la locura en la época clásica. México: FCE.

Foucault, M. (2015). Vigilar y castigar. El nacimiento de la prisión. México: Siglo XXI.

Garrocho, C. y Campos, J. (2015). Segregación socioespacial de la población mayor en la Ciudad de México, 2000-2010. En La situación demográfica de México 2015 (pp. 169-198). México: CONAPO.

Goffman, E. (2001). Internados. Buenos Aires: Amorrortu.

González, K. (2015). Envejecimiento demográfico: análisis comparativo entre las entidades federativas. En La situación demográfica de México (pp. 113-129). México: CONAPO.

Iglesias, J. (2001). La soledad en las personas mayores. Influencias personales, familiares y sociales, análisis cualitativo. Madrid: IMSERSO.

Leinaweaver, J. (2019). Hacia una antropología de la ingratitud: notas a partir de las relaciones de parentesco andino. Etnografías Contemporáneas, 4(8), 175-200.

Ley de los derechos de las personas adultas mayores (2002). México: H. Congreso de la Unión.

Mallimaci, F. y Giménez, V. (2012). Historia de vida y métodos biográficos. En I. Vasilachis (coord.), Estrategias de investigación cualitativa (pp. 175-212). Buenos Aires: Gedisa.

Parres, R. (2003). La vejez. En E. Dallal (coord.), De la edad adulta la vejez (pp. 303-335). México: Plaza y Valdés.

Paz, C. (2010). El encierro: ¿protección o mutilación del ser humano? Casa del tiempo, 31(3), 57-62.

Peláez, O. (2009). Descripción y proyección de la esperanza de vida al nacimiento en México (1900-2050). Estudios Demográficos y Urbanos, 24(2), 469-492. https:// doi.org/10.24201/edu.v24i2.1341

Powell, L. (2010). The Power of Global Aging. Ageing International, 35, 1-14. https:// doi.org/10.1007/s12126-010-9051-6 
Reyes, L. (2012). Etnogerontología social: la vejez en contextos indígenas. Revista del Centro de Investigación de la Universidad la Salle, 10(38), 69-83. Recuperado de http://revistasinvestigacion.lasalle.mx/index.php/recein/article/view/90

Ríos, J., Grajales, J. y Valle, L. (2016). Influencia de la institucionalización del adulto mayor en el desempeño de la memoria declarativa Visuo-Verbal asociada a contenido emocional. Katharsis, 22, 35-62. https://doi.org/10.25057/25005731.814

Robles, L., Vázquez, F., Reyes, L. y Orozco, I. (2006). Miradas sobre la vejez. Un enfoque antropológico. México: Plaza y Valdez / El Colegio de la Frontera Norte.

Ruiz, A., Alter, J., Porta, N., Duaso, P., Solé, M. y Requesens, N. (2001). Violencia doméstica: prevalencia de sospecha de maltrato a ancianos. Atención Primaria, 27(5), 331-334.

Ruiz, F. y Hernández, M. (2009). El abandono del adulto mayor como manifestación de violencia intrafamiliar. Archivos en Medicina Familiar, 11(4), 147-149. https:// doi.org/10.1016/S0212-6567(01)79376-6

Secretaría de Desarrollo Social (2010). Diagnóstico sobre la situación de vulnerabilidad de la población de 70 años y más. México: SEDESOL.

Welti, C. (2018). El Estado, la familia y el mercado: arreglos institucionales para atender las necesidades generadas por el envejecimiento demográfico. Papeles de Población, 95, 9-42. https://doi.org/10.22185/24487147.2018.95.02 